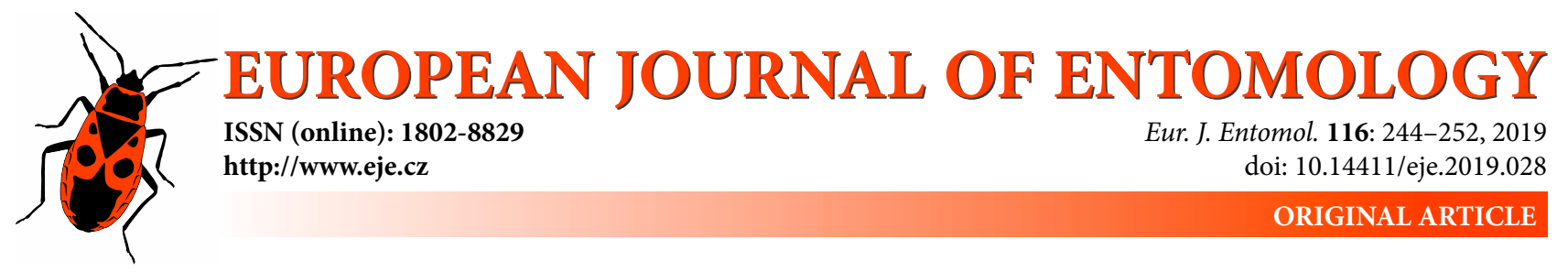

\title{
First North American record of an unnamed West Palaearctic Agrilus (Coleoptera: Buprestidae) infesting European beech (Fagus sylvatica) in New York City, USA
}

\author{
MARc F. DIGIROLOMO ${ }^{1}$, EduARd JENDEK ${ }^{2}$, VASILY V. GREBENNIKOV ${ }^{3}$ and Oto NAKLÁdAL ${ }^{2}$ \\ ${ }^{1}$ USDA Forest Service, Eastern Region, State and Private Forestry, Forest Health, 271 Mast Rd., Durham, NH 03824, USA; \\ e-mail: marc.f.digirolomo@usda.gov \\ ${ }^{2}$ Czech University of Life Sciences Prague, Faculty of Forestry and Wood Sciences, Department of Forest Protection and \\ Entomology, Kamýcká 1176, 16521 Praha 6 - Suchdol, Czech Republic; e-mails: jendeke@gmail.com, nakladal@fld.czu.cz \\ ${ }^{3}$ Canadian Food Inspection Agency, 960 Carling Av., Ottawa, K1A 0C6, Canada; e-mail: vasily.grebennikov@canada.ca
}

Key words. Coleoptera, Buprestidae, Agrilus, North America, New York City, invasive alien species, Fagus

\begin{abstract}
This paper reports a non-native Agrilus wood-boring jewel beetle reared from a stressed and non-native European beech (Fagus sylvatica) tree growing in New York City, USA. Results of two analyses using 759 DNA barcodes of Agrilus corroborate the morphology-based interpretation that this is the first North American record of an unnamed species from the $A$. roscidus species-group native to the Western Palaearctic. Taxonomy of the entire species-group requires revision, therefore we postpone formal description of the new species and refer to it as Agrilus sp. 9895. This is the $12^{\text {th }}$ non-native Agrilus established in North America. Prior to our study, members of the A. roscidus species-group were not known to develop in Fagus, therefore we hypothesise whether our record is a host plant shift linked to the human-mediated transatlantic dispersal, or a case of an elusive beetle escaping detection in Fagus in its unknown native range. All 759 herein analysed DNA barcodes of Agrilus (including, when present, specimen images and georeferences) are available online at dx.doi.org/10.5883/DS-VGDS010.
\end{abstract}

\section{INTRODUCTION}

This paper was triggered by the detection of an unusual looking wood-boring jewel beetle (Coleoptera: Buprestidae) found in New York City (NYC), USA. One larva and eight seemingly conspecific adults were obtained between August 2017 and August 2018 from twigs and small branches (Figs 1A-C) of a mature European beech (Fagus sylvatica L.) (Fig. 1D), while one more adult was subsequently trapped on the same standing tree (see Material and methods). The specimens (Figs 2A-B) belonged to the gigantic genus Agrilus Curtis, 1825, which is unique in the Animal Kingdom for having $>3,000$ valid species (Jendek \& Grebennikov, 2011). Many Agrilus species capitalize on their human-mediated transoceanic dispersal and successfully establish on new continents (Hoebeke et al., 2017 and references therein for North America; Hizal \& Arslangündoğdu, 2018 for Europe). To date, 11 Agrilus species-group taxa found in America north of Mexico are thought to be non-native (Jendek \& Grebennikov, 2009; Jendek et al., 2015; Hoebeke et al., 2017), while at the turn of the millennium this number was only six (Table 1). Most infamous of the new arrivals is Agrilus planipennis Fairmaire, 1888, native to East Asia and colloquially known as "emerald ash borer". This species has invaded North America (Haack et al., 2002) and Europe (Baranchikov et al., 2008) causing widespread mortality of ash and was assessed as "the most costly biological invasion by an exotic forest insect to date" (Herms \& McCullough, 2014). Notably, the herein reported NYC Agrilus was attacking a nonnative tree growing in the heart of a large urban conglomerate not too distant from a major international trade port. These observations were consistent with a hypothesis that the unknown NYC Agrilus might be yet another unwanted human-mediated addition to the Nearctic fauna, potentially capable of inflicting damage to an important urban tree in parts of North America.

Preliminary morphology-based identification (see Material and methods and Results) suggested that the NYC Agrilus adults belong to the A. roscidus species-group (ARSG, as defined in Jendek \& Grebennikov, 2011) with 13 species-group taxa (Table 2). Members of the ARSG are externally similar among themselves and their reliable species-level morphological identification is based on male characters. The most important diagnostic characters are body size and color, shape of antennomeres, shape of pronotum, type and length of prehumerus, shape of aedeagus 

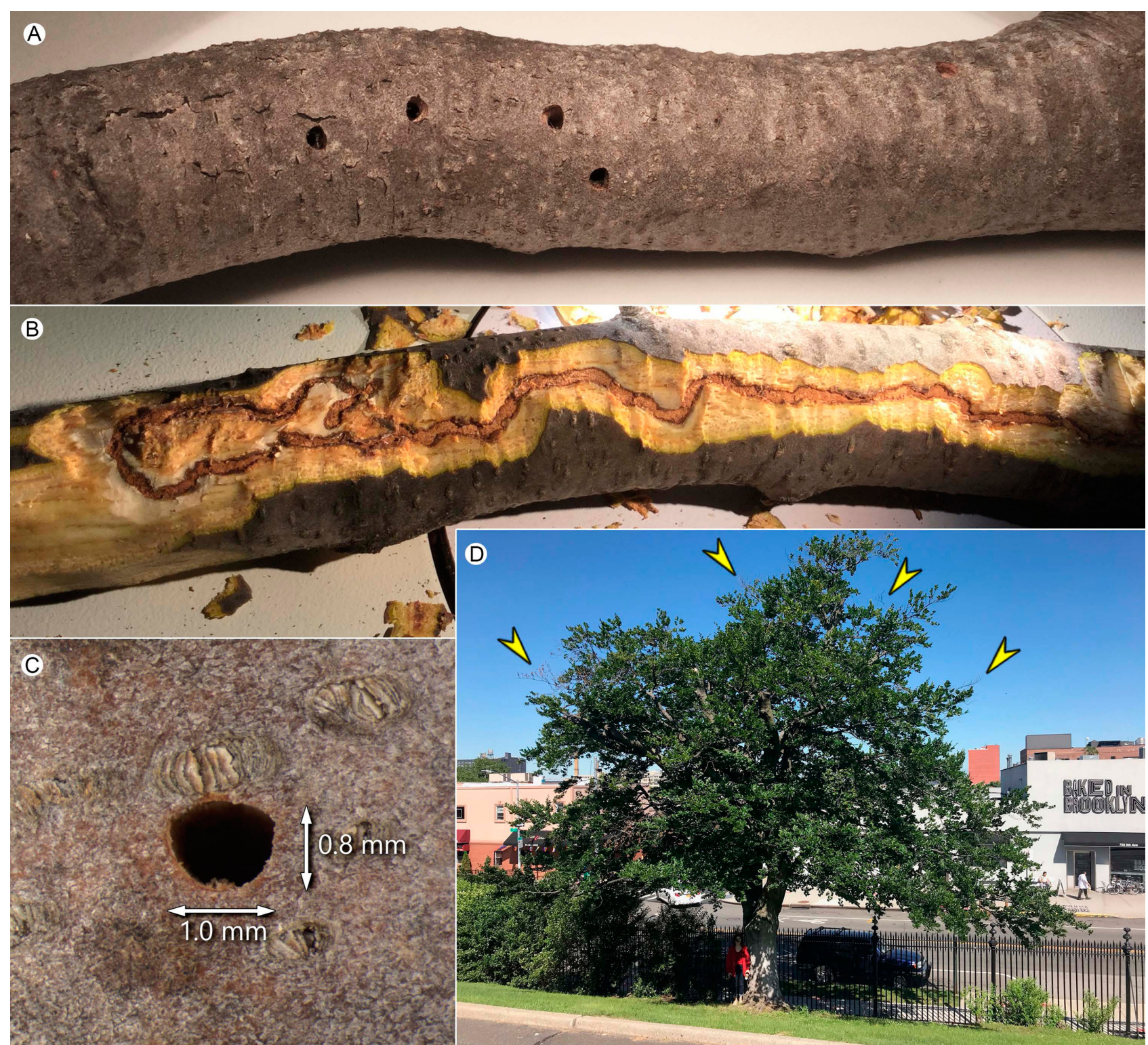

Fig. 1. Signs of damage made by Agrilus sp. 9895 in New York City, USA. A - adult exit holes in twig (diameter 9 mm) removed from the rearing barrel; B - larval feeding gallery in twig (diameter $9 \mathrm{~mm}$ ); C - D-shaped exit hole of Agrilus sp. 9895 characteristic to the genus; D - infested Fagus sylvatica tree in Green-Wood Cemetery, Brooklyn, New York City, USA (arrows indicate damage by Agrilus sp. 9895).

and other male sexual characters. This clade (Kelnarova et al., 2019) is native to the West Palaearctic Region (Fig. 3C), geographically overlaps with the native range of Fagus sylvatica, and has never been reported from North America. Remarkably, none of the ARSG members has been recorded to develop on Fagus (Jendek \& Poláková, 2014). The likelihood of such a biological fact having passed undocumented in Europe is very low. The alternative of a biologically significant and relatively rare switch to a new host plant has a comparably low plausibility. If the latter is the case, it might be linked to the physiological stress and genetic bottle-neck of a recent transatlantic and likely human-mediated dispersal, akin to the concept of ecological fitting (Janzen, 1985; Agosta \& Klemens, 2008) which has been suggested as the mechanism behind the recently documented host-switch of emerald ash borer infesting Chionanthus (Cipollini \& Peterson, 2018).
The goal of this paper is to document the detection of an unknown Agrilus wood-borer in NYC and to unfold a sequence of analytical steps towards its identification and testing of our six initial predictions.

Desiring to operate within the realm of empirical falsification of hypotheses (Popper, 1959), before the analysis we predicted that (1) the adults and the larva obtained from $F$. sylvatica growing in NYC are conspecific; (2) they belong to a species not native to North America; (3) the species is a member of the West Palaearctic ARSG; (4) the species can be taxonomically identified; (5) human-mediated dispersal was the likeliest factor accounting for their arrival and (6) its development in Fagus is most likely a relatively recent evolutionary novelty attributable to the effect of the transatlantic dispersal. These six predictions form a logical framework of hypotheses, which we tested using DNA and morphological data. 


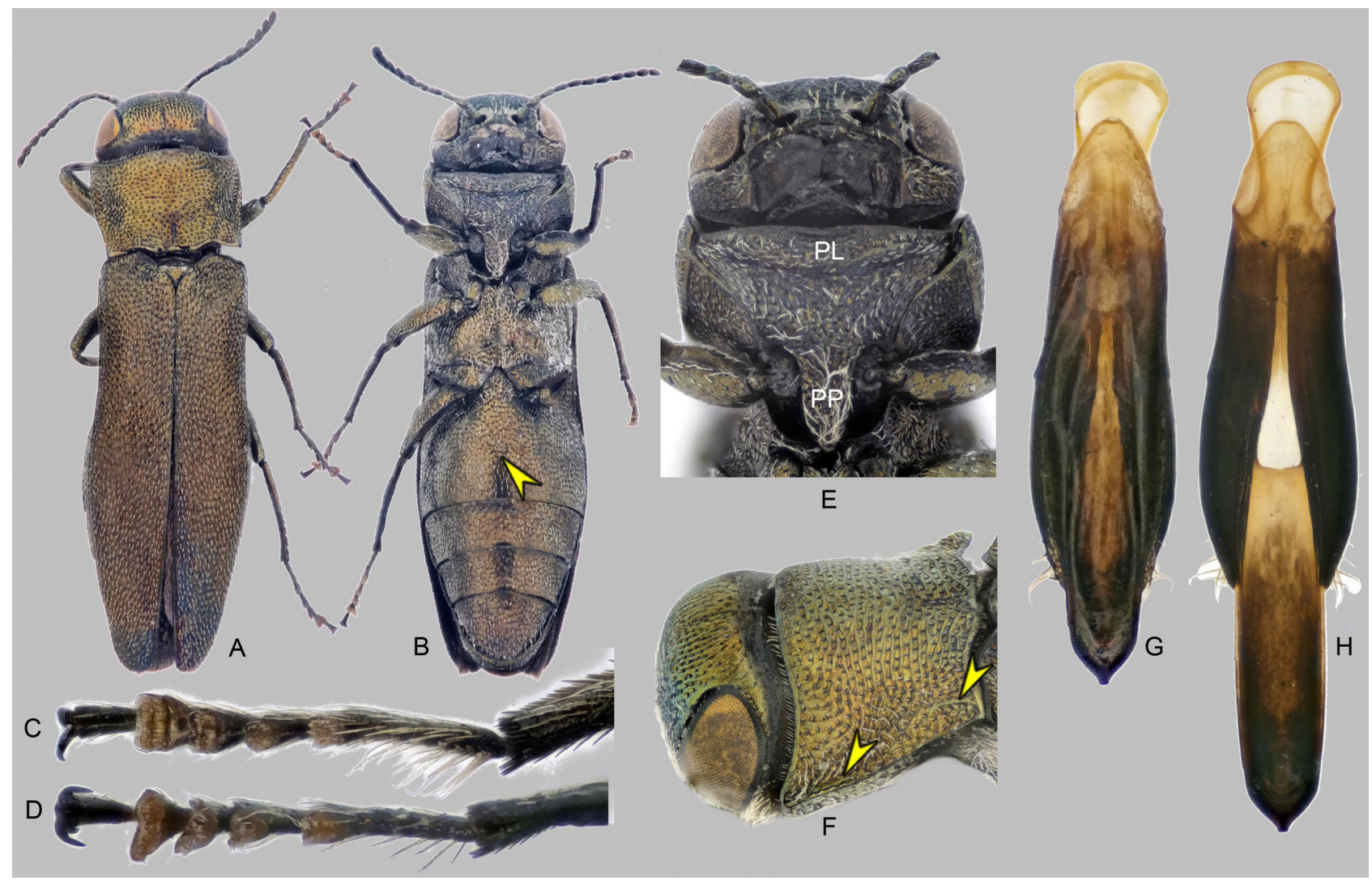

Fig. 2. Adult morphology of Agrilus sp. 9895 (A-B, D-H, specimen 9916) and A. roscidus (C). A, B - habitus dorsal (A) and ventral (B), body length $3.7 \mathrm{~mm}$; $\mathrm{C}-\mathrm{D}$ - metatarsi; $\mathrm{E}$ - prosternum ( $\mathrm{PL}$ - prosternal lobe, $\mathrm{PP}$ - prosternal process); $\mathrm{F}$ - head and pronotum (left dorsolateral view), arrows indicate anterior and posterior part of prehumerus; $\mathrm{G}-\mathrm{H}$ - aedeagus dry (G) and embedded in water soluble mounting medium Dimethyl Hydantoin Formaldehyde $(\mathrm{H})$.

\section{MATERIAL AND METHODS}

\section{Specimen discovery and rearing}

This study resulted from a novel monitoring program (DiGirolomo et al., in prep.) targeting wood-boring insects attacking planted landscape trees and shrubs in Green-Wood Cemetery, an accredited arboretum in the borough of Brooklyn, NYC which has an ongoing planting program throughout the grounds. The donor Fagus tree was selected because it exhibited signs of crown stress and branch dieback. Branches were pruned and placed in an empty rearing barrel with an externally mounted collection cup containing propylene glycol as a preservative in spring 2017. The collection cup was emptied in August 2017 and specimens were examined in early 2018 , while the barrel remained sealed for additional rearing. Three seemingly conspecific males and two females of an unknown Agrilus were detected in the initial sample. Images of the specimens taken by MD were sent to $\mathrm{E}$. Richard Hoebeke (University of Georgia) for identification, who then forwarded them to EJ. Three specimens were sent to VG for the first round of DNA barcoding (see below). In spring 2018, more branches were pruned from the original tree, as well as several Fagus sylvatica trees in its vicinity, and placed in rearing barrels. Also at this time, two purple prism traps baited with z-3-hexanol were hung in the crown of the original tree. In August 2018 the original barrel was opened and swept out to reveal two more Agrilus adults, and the additional barrel collection cups

Table 1. Currently known species of Agrilus introduced to North America. Only proven larval host plants are given (from Jendek \& Poláková, 2014 except * from Cipollini \& Rigsby, 2015).

\begin{tabular}{lcc}
\hline Species & Larval host plant & First reported in North America \\
\hline A. sinuatus (Olivier, 1790) & Crataegus, Malus, Mespilus, Prunus, Pyrus, Sorbus & Anonymous, 1894 \\
\hline A. cuprescens (Ménétriés, 1832) & Rosa, Rubus & Weiss, 1914 \\
\hline A. cyanescens (Ratzeburg, 1837) & Lonicera, Symphoria, Symphoricarpos, Rhamnus & Frost, 1922 \\
\hline A. derasofasciatus Lacordaire, 1835 & Vitis & Malkin, 1941 \\
\hline A. hyperici (Creutzer, 1799) & Hypericum & $\begin{array}{c}\text { Intentionally introduced in 1953 } \\
\text { (Campbell \& McCaffrey, 1991) }\end{array}$ \\
\hline A. pilosovittatus Saunders, 1873 & Wisteria & Hespenheide, 1968 \\
\hline A. planipennis Fairmaire, 1888 & Fraxinus, Chionanthus & Haack et al., 2002 \\
\hline A. subrobustus Saunders, 1873 & Albizia & Westcott, 2007 \\
\hline A. sulcicollis Lacordaire, 1835 & Quercus, Fagus & Jendek \& Grebennikov, 2009 \\
\hline A. ribesi Schaefer, 1946 & Ribes & Jendek et al., 2015 \\
\hline A. smaragdifrons Ganglbauer, 1889 & Ailanthus & Hoebeke et al., 2017 \\
\hline Agrilus sp. 9895 & Fagus & 2019 \\
\hline
\end{tabular}




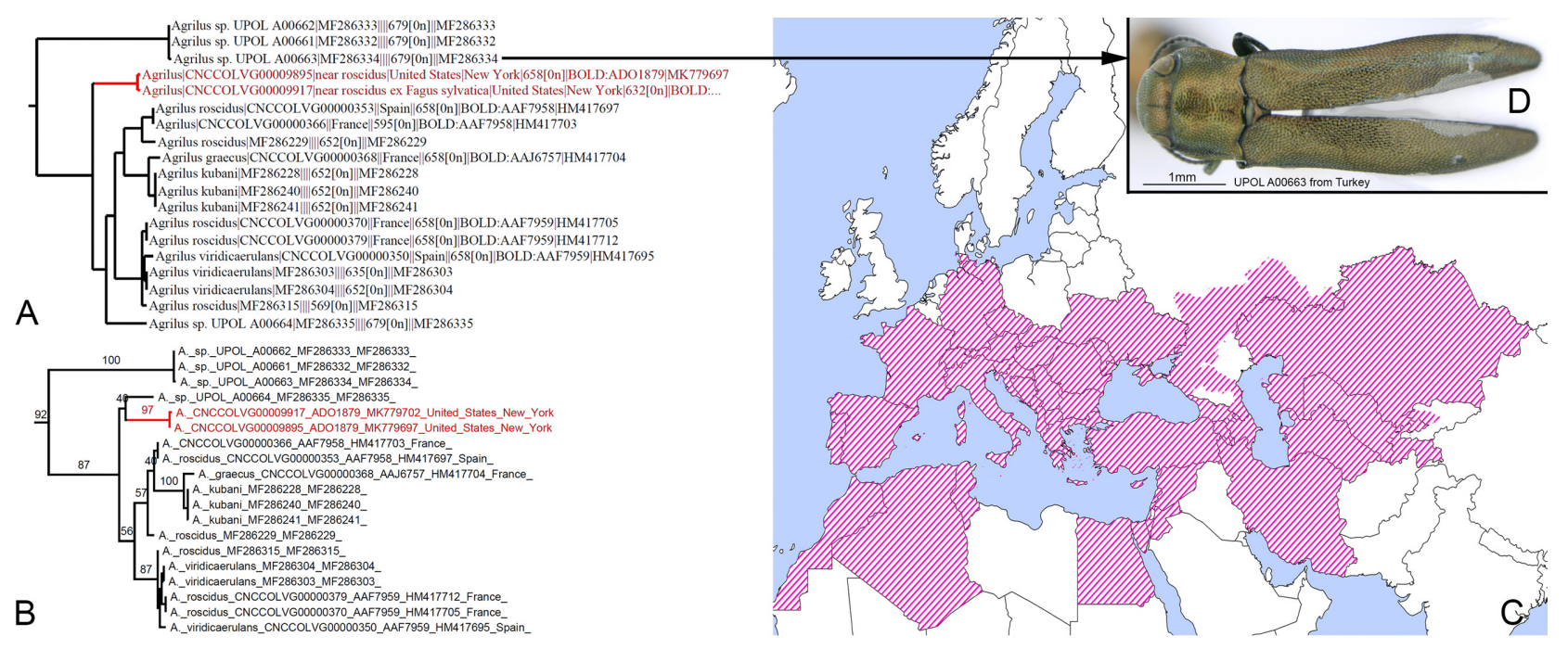

Fig. 3. The relevant parts (the $A$. roscidus species-group) of the resulting topologies of two DNA analyses (A, B), western Palaearctic distribution of $A$. roscidus (which encompasses the ranges of all other members of the $A$. roscidus species-group except for the central Asian A. chlorophyllus) (C), and image of unnamed Agrilus sp. from Turkey forming sister clade to all other members of the group (D). A - Neighbour Joining analysis (A1); B - Maximum Likelihood analysis (A2). Two sequenced specimens of NYC Agrilus sp. 9895 are in red. Digits on branches are bootstrap values. Label data include taxon, sample ID, country, province/state, sequence length, barcode cluster (BIN) and GenBank accession number. Some of the accompanying data are missing for sequences obtained from public sources.

were emptied to reveal one Agrilus adult. At this time, branches were pruned directly from the tree and excavated to reveal one live larva. These four specimens were subjected to the second round of DNA barcoding. The prism traps were also checked in August 2018 to reveal one adult Agrilus which matched the morphology of the unknown specimens. Subsequent inspection of the rearing barrel contents revealed larval galleries (Fig. 1B) and D-shaped exit holes (Figs 1A, C) on branches, characteristic for Agrilus. Altogether nine Agrilus adults and one larva were collected; all of them (except for a single trap-captured female) were recovered from rearing barrels loaded with the pruned branches of a single stressed beech tree. These specimens are kept in the following collections: Canadian National Collection of Insects, Arachnids and Nematodes, Ottawa, Canada; Smithsonian Institution National Museum of Natural History, Washington, DC, USA; USDA Forest Service Durham Field Office, Forest Insect
Collection, Durham, NH. USA; Collection of Eduard Jendek, Bratislava, Slovakia.

\section{Morphological study}

The larva was identified to the genus level using diagnostic characters of the genus Agrilus (i.e. Chamorro et al., 2012); its species-level identification was impossible for the lack of morphology-based diagnostic tools. Adult specimens posted to EJ were compared with those of over 1,500 Agrilus species in his collection using external body characters and those of male genitalia.

\section{DNA barcoding}

A total of seven NYC Agrilus specimens (six adults and one larva), all of them obtained from the same tree, were subjected to DNA barcoding. This method targets 658 base pairs of the 5'end of the mitochondrial cytochrome oxidase subunit I (COI)

Table 2. Characteristics of 13 nominal species-group taxa of the Agrilus roscidus species-group. Only proven larval host plants are given (from Jendek \& Poláková, 2014). Body length is in mm.

\begin{tabular}{|c|c|c|c|}
\hline Species & Distribution & $\begin{array}{l}\text { Larval host } \\
\text { plant }\end{array}$ & $\begin{array}{l}\text { Body } \\
\text { length }\end{array}$ \\
\hline A. chlorophyllus Abeille de Perrin, 1904 & $\begin{array}{c}\text { Asia: Iran; Israel; Kyrgyzstan; Syria; Tajikistan; Turkey; } \\
\text { Turkmenistan; Uzbekistan. }\end{array}$ & Pistacia & $3.4-5.3$ \\
\hline gianassoi Magnani \& Niehuis, 1994 & $\begin{array}{l}\text { Asia: Cyprus. } \\
\end{array}$ & Pistacia & $3.9-4.6$ \\
\hline A. graecus Obenberger, 1916 & $\begin{array}{l}\text { Europe: Austria; Czech Republic; France; Greece; Hungary; Italy; } \\
\text { Montenegro; Serbia; Slovakia; Slovenia; Switzerland. }\end{array}$ & Viscum & $4.8-6.5$ \\
\hline A. jacetanus Sánchez \& Tolosa, 2004 & Europe: Spain. & Viscum & $5.4-7.0$ \\
\hline ani Bílý, 1991 & Europe: Austria; Czech Republic; Hungary; Slovakia. & Loranthus & $4.9-6.2$ \\
\hline kutahyanus Królik, 2002 & Asia: Turkey. & Viscum & $5.9-7.4$ \\
\hline A. margotanae Novak, 2001 & Asia: Cyprus. & $\begin{array}{l}\text { Crataegus, } \\
\text { Prunus }\end{array}$ & $3.5-4.7$ \\
\hline A. marozzinii Gobbi, 1974 & $\begin{array}{l}\text { Africa: Algeria. Asia: Turkey. Europe: Albania; Bulgaria; Croatia; } \\
\text { France; Greece; Italy; Montenegro; Serbia. }\end{array}$ & Pistacia & $4.5-6.0$ \\
\hline A. rhoos Królik \& Niehuis, 2003 & Asia: Turkey. & Rhus & $4.3-7.2$ \\
\hline tter, 1857 & Western Palaearctic (Fig. 3). & Polyphagous & $4.5-6.5$ \\
\hline A. sylviae Niehuis, 1992 & Asia: Israel; Turkey. & Pistacia & $4.2-5.2$ \\
\hline A. viridicaerulans rubi Schaefer, 1937 & $\begin{array}{l}\text { Africa: Algeria. Asia: Turkey. Europe: Albania; Bosnia and Herzegovina; } \\
\text { Bulgaria; Croatia; France; Germany; Greece; Italy; Macedonia; } \\
\text { Montenegro; Portugal; Serbia; Slovakia; Slovenia; Spain; Switzerland. }\end{array}$ & Rubus & $3.6-5.1$ \\
\hline A. viridicaerulans s. str. Marseul, 1868 & Asia: Israel; Jordan; Lebanon; Syria; Turkey. & Rubus & $3.6-5.1$ \\
\hline
\end{tabular}


gene (Hebert et al., 2003). All laboratory procedures followed the standard protocol of the Canadian Centre for DNA Barcoding (http://ccdb.ca). Six sequenced adults had unique specimen numbers 9893, 9894, 9895, 9916, 9917 and 9949; the larval number was 9950. Sample IDs of these specimens in the Barcode of Life Database (BOLD, Ratnasingham \& Hebert, 2007) are in the format CNCCOLVG0000XXXX (XXXX correspond to unique four digit specimen numbers). Only three specimens amplified: the adults 9895 and 9917, and the larva 9950. In preparation for the subsequent DNA-based analysis, seven adult specimens of $A$. smaragdifrons Ganglbauer, 1889, a species native to China and recently reported from USA (Hoebeke et al., 2017), were DNA barcoded following the method described above; their specimen numbers are 9324-30 (all of them amplified, except for 9330). The COI length for all the amplified specimens was $658 \mathrm{bp}$ except for 9917 (632 bp) and 9950 (620 bp). A list of these 14 Agrilus specimens submitted for DNA barcoding, including their images, georeferences, primers, sequences, original electropherograms and other relevant laboratory data can be seen online in the publicly accessible dataset on the BOLD portal (doi: dx.doi. org/10.5883/DS-VGDS009). All GenBank accession numbers for the nine newly generated DNA barcodes are MK779696-704.

\section{Design and implementation of phylogenetic analyses}

Two analyses, both utilizing the same DNA barcode fragment, were designed for this study. For quality control purposes, we downloaded all Agrilus DNA barcodes that were between 400 and $680 \mathrm{bp}$ in length publicly available from BOLD. The initial search (on March 27, 2019) for the keyword "Agrilus" retrieved 757 such records (of them 232 with Sample ID in the format CNCCOLVG0000XXXX were generated by us in Ottawa and utilized in Kelnarova et al., 2019). Five of the 757 records were marked by BOLD as misidentifications or contaminations and were excluded. The remaining 752 DNA barcodes were combined with the nine newly generated, and then aligned using the MAFFT algorithm (Kuraku et al., 2013; Katoh et al., 2017) implemented online (https://mafft.cbrc.jp/alignment/server/). The resulting alignment contained a single frame-shifting gap caused by two insertions in sequences MF543038 and MF543039; they were interpreted as potential pseudogenes and excluded. The remaining 759 Agrilus DNA barcodes were re-aligned without detecting insertions or deletions and were considered of sufficient quality to be analysed. These 759 Agrilus DNA barcode sequences (including, when available, specimen images, georeferences, primers, original electropherograms and other relevant laboratory data) can be seen online in the publicly accessible dataset on the BOLD portal (doi: dx.doi.org/10.5883/DS-VGDS010).

Analysis 1 (A1) was a non-phylogenetic clustering utilizing a computationally simplified and rapid BOLD online tree-building algorithm. The 759 Agrilus DNA barcodes were re-aligned and grouped using BOLD alignment and Neighbour Joining (NJ) clustering utilizing the Kimura 2 parameter, as implemented in the online BOLD tree-building engine.

Analysis 2 (A2) was a statistically more elaborate alternative to A1. Since Agrilini are likely non-monophyletic and since the genus Pachyschelus Solier, 1833 is the most reliably documented sister to monophyletic Agrilus (Evans et al., 2015), the 759-terminal Agrilus-only matrix was enlarged with a DNA barcode of $P$. undulatus Waterhouse, 1889 (GenBank accession number KM364330). The resulting dataset of 760 DNA barcodes was downloaded from BOLD as a Fasta file and aligned using the MAFFT algorithm described above. The resulting alignment contained no frame shifts or insertions/deletions. A rooted topology was built using the Maximum Likelihood (ML) approach as implemented in the CIPRES Science Gateway online platform
(Miller et al., 2010; http://www.phylo.org/) using the RAxML 8 tool (Stamatakis, 2014) and the CAT approximation to the widely used GTR $+\mathrm{G}$ model. Support values were obtained based on 1000 bootstrap replicates (Felsenstein, 1985; Stamatakis et al., 2008) and the topology was visualized in FigTree v1.4.0 (Rambaut, 2019).

\section{RESULTS}

\section{Adult morphological description}

Small (3.7-3.9 mm) and robust Agrilus (Figs 2A-B), body dorsally dark olivaceous-brown, head and pronotum with golden tinge in male and carmine in female, frons golden-blue in male and carmine in female. Head large, strongly arcuate and without medial impression, vertex subparallel rugoso-punctate. Eyes smaller than half width of vertex (dorsal view), antennae obtusely serrate from antennomere 4, reaching just beyond anterior pronotal angles. Pronotum strongly transverse, widest at anterior margin, sides bisinuate; posterior angles subrectangular and sharp on tip. Anterior pronotal lobe widely arcuate and at level with anterior angles. Pronotal disk strongly convex with fine medial impression disrupted at middle and with deeper and narrow lateral impressions. Prehumerus (Fig. 2F) bisinuate and extending from posterior to anterior pronotal angle; carinal in basal and apical part and obsolete in middle. Elytra with regular, white, sparse and recumbent pubescence, elytral apices widely separately arcuate. Prosternal lobe (Fig. 2E) arcuate and finely arcuately emarginate near top (postero-ventral view); prosternal process slender (Fig. 2E), slightly attenuate between procoxae, with obtuse lateral angles, disk with erect white pubescence; metasternal projection without impression. Basal ventrite in male with indication of two medial tubercles (Fig. 2B), pygidium arcuate on apex, sternal groove on apex of last ventrite arcuate. Metatarsomere 1 in male with row of long setae on lower side (Fig. 2D). Aedeagus (Figs. 2G-H) robust, widest before apex; medial lobe wider than parameres and with small projection on tip; ovipositor markedly elongate.

\section{Results of phylogenetic analyses}

The NJ clustering of 759 terminals (analysis A1) produced a topology depicted in Fig. S1; its part containing the two NYC adults is depicted in Fig. 3A. Both sequenced NYC adults (9895 and 9917) share the same unique haplotype and cluster with the rest of ARSG. The larva 9950 clusters with specimens of A. carpini Knull, 1923 and A. bilineatus (Weber, 1801) (Fig. S1). The ML phylogenetic analysis (analysis A2) of 760 terminals produced a topology depicted in Fig. S2; its part containing the two NYC adults is depicted in Fig. 3B. Grouping of all three sequenced NYC specimens in A2 is consistent with the results of analysis A1, while the bootstrap support for monophyletic ARSG is $92 \%$ (and $100 \%$ for the clade formed by A. carpini, A. bilineatus and NYC larva 9950).

\section{DISCUSSION}

Interpretation of the herein presented results lead to conclude that: 
Prediction 1 (the adults and the larva obtained from NYC F. sylvatica are conspecific) is strongly rejected. The larva is not conspecific with the adults and instead belongs to the native $A$. bilineatus, known only from Quercus and Castanea (Jendek \& Poláková, 2014). The closely related $A$. carpini (possibly even a synonym of $A$. bilineatus) breeds in Fagus. Thus, multiple species of Buprestidae are utilizing the same tree, likely due to the tree undergoing significant stress and dieback. The larva was also obtained from a branch larger than those containing the exit holes and galleries of the adult specimens. It is possible that the unknown Agrilus is restricted to smaller twigs and branches.

Prediction 2 (NYC Agrilus belong to a species not native to North America) is strongly supported for the adult specimens, since they do not resemble any North American congeners. Compared to other Nearctic Agrilus, those reared from NYC Fagus are very distinct by their small size, robust body, small eyes, distinctly transverse pronotum widest at anterior angles, shape of prehumerus and by the male sexual characters. The DNA-based identification also did not reveal any North American Agrilus related to the NYC specimens.

Prediction 3 (the NYC Agrilus species is a member of the West Palaearctic ARSG) is strongly supported from two independent lines of evidence: adult morphology and DNA barcode. All NYC adult Agrilus specimens uniquely fit the morphological diagnosis of the species group (Jendek \& Grebennikov, 2011), while their DNA barcodes are nested within a monophyletic and strongly supported ARSG clade (Figs 3A, B). Three unnamed Agrilus sp. (UPOL A00661663, Fig.3D) from Turkey belong to the ARSG (based on both morphology and DNA barcode) and form its basalmost group.

Prediction 4 (the NYC species can be taxonomically identified) is, surprisingly, rejected. We are unable to assign the NYC adult Agrilus to any nominal species. Any further taxonomic identification beyond the ARSG is currently impossible, since:

(1) NYC adults do not belong to any ARSG taxon with a single and unrelated host plant (such as Pistacia, Viscum, Rhus, Rubus; see Table 2). Moreover, some of these species are morphologically distinct and dissimilar (A. chlorophyllus Abeille de Perrin, 1904, A. marozzinii Gobbi, 1974), distinctly larger (A. greacus Obenberger, 1916, A. jacetanus Sobrino Sánchez \& Tolosa Sánches, 2004, A. kubani Bílý, 1991, A. rhoos Królik \& Neihuis, 2003) or restricted geographically (A. gianassoi Magnani \& Niehuis, 1994)

(2) Fagus (or even Fagaceae) has never been previously recorded as a larval host plant for the ARSG. The NYC adults might perhaps be considered as a new ecological form of the extremely polyphagous $A$. roscidus Kiesenwetter, 1857, but they are distinctly smaller $(3.7-3.9 \mathrm{~mm}$ versus $4.5-6.5 \mathrm{~mm}$ ), have the proximal metatarsomere in males with sparse setae (Fig. 2D), and are not densely pubescent, as in $A$. roscidus (Fig. 2C).

(3) By the small size, bronze color, and by the shape of the aedeagus, the NYC Agrilus resemble A. margotanae
Novak, 2001 (known only from Cyprus and developing in Crataegus and Prunus); it differs from the latter by having widely arcuate elytral apices and by lacking white pubescence in the middle part of the pronotum.

(4) DNA data, owing to the scarcity of sequenced ARSG specimens (and doubtful taxonomic identity of some; see Figs 3A,B showing records lacking species-group names), are inconclusive.

Morphologically, the NYC specimens are sufficiently distinct from all named members of ARSG to warrant description of a new species, while the results of the DNA analyses are consistent with this interpretation. We do not formally describe this unnamed species for two reasons. First, it is premature to establish the type locality outside of the natural species' range and before the latter is even known. Second, taxonomy of the entire ARSG is unresolved and must be revised as a whole; the latter task, however, is beyond our scope. When so revised, some currently accepted species of the ARSG might be incorporated into the wider concept of $A$. roscidus, or, alternatively, new nominal species will emerge for ecological forms currently lumped into $A$. roscidus. Pending analysis of larger material with known larval hosts and DNA data aimed to stabilize taxonomy for the ARSG, we temporarily designate the herein reported NYC members of ARSG as Agrilus sp. 9895.

The only key to North American Agrilus spp. is Fisher (1928) which is severely outdated. In the northern United States and Canada, Bright (1987) is useful but also outdated. In both of these keys, Agrilus sp. 9895 will key readily to $A$. cuprescens [listed as $A$. viridis var. fagi in Fisher (1928) and A. aurichalceus in Bright (1987)]. Agrilus sp. 9895 can easily be distinguished from this species by its much smaller size, the characters of the aedeagus previously mentioned, and by the host.

Prediction 5 (human-mediated dispersal was the likeliest factor accounting for the arrival of Agrilus sp. 9895 to North America) is supported, since taxonomic and phylogenetic placement of Agrilus sp. 9895 in the ARSG strongly suggests its West Palaearctic origin. Accepting that the breadth of the Atlantic Ocean represents an insurmountable natural dispersal barrier for such terrestrial organisms as Agrilus, we must, therefore, evoke transportation by means of human agency.

Prediction 6 (development in Fagus is most likely a recent evolutionary novelty attributable to the effect of the transatlantic dispersal) could not be decisively tested. $\mathrm{Ag}$ rilus beetles are conservative in their preferred larval host plants and, therefore, such information considerably facilitates species identification. Moreover, most species are known from only a single host plant. Within the ARSG $A$. roscidus is polyphagous, while all other species are known to develop in only one or two plant genera of Anacardiaceae (Rhus, Pistacia), Rosaceae (Rubus, Prunus, Crataegus), Santalaceae (Viscum) and Loranthaceae (Loranthus) (see Table 2). Despite a few published erroneous Quercus records (Péneau, 1911; Browne, 1968), no members of the ARSG were known to develop on Fagaceae. Niehuis 
\& Tezcan (1993) reported three adult records of $A$. rosci$d u s$ from Quercus in Turkey. These records are questionable and could not be verified, but it is not excluded that they concern Agrilus sp. 9895 and perhaps warrant further investigation. A single larval record from Quercus (Bílý, 2002) was likely a result of the misattribution of $A$. $k u$ bani developing in Loranthus, a parasitic plant growing on Quercus (S. Bílý, pers. comm.). Our record of Agrilus sp. 9895 developing on Fagus might be explained in two ways. First, Agrilus sp. 9895 in its native range indeed develops in Fagus and this remains undocumented. Although rare, the discovery of a new species in the ARSG in a previously unknown host family has occurred (Bílý, 1991). Alternatively, evoking a host plant switch unique to the NYC population and linked to the dispersal event is equally plausible. Host switching due to genotypic variation, environmental stimuli, or some form of ecological fitting has been documented in parasitic fungi (Rossi, 2011) and insects (Jones et al., 2015; Hanski et al. 2008; Calcagno et al., 2007), but often occurs with new hosts that are closely related to or share chemical features of ancestral hosts (Cipollini \& Peterson, 2018). Agrilus may possess the ability to switch hosts in the absence of the primary host (Bernhard et al., 2005) following an immigration to a non-native realm. Emerald ash borer developing in Chionanthus (Cipollini, 2015; Cipollini \& Rigsby, 2015) has been described as a likely case of host switching by ecological fitting (Cipollini \& Peterson, 2018). Both hypotheses require significant assumptions, and having no third alternative, either explanation seems plausible.

\section{CONCLUDING REMARKS}

This study is peculiar in three aspects. Firstly, since the beginning of the millennium, alien Agrilus are discovered in North America with the scattering rate of one in about every three years (increase from six to 12 by 2019). One of them, A. planipennis, the infamous emerald ash borer, has caused unparalleled economic losses estimated at over 1.6 billion USD in the United States annually (Aukema et al., 2011), ecological impacts (Klooster et al., 2018), and threats to Native American cultural traditions (Costanza et al., 2017), all within about 25 years of establishment (Siegert et al., 2014). It might, therefore, be a matter of time before the sad story of mass North American tree killing is repeated by another immigrant Agrilus. Secondly, the herein reported Agrilus sp. 9895 belongs to an unnamed species first found outside its native range and, therefore, represents an "unknown unknown" unidentifiable to a species level. This sobering consideration of taxonomic inadequacy resembles a situation when the immigrant population of $A$. planipennis first detected in both Canada and USA could not be domestically identified for the lack of voucher specimens and adequate knowledge. Thirdly, here we hypothesise the capacity of an immigrant Agrilus to rapidly switch to a new host plant. Whether a host switch has occurred, or this obscure beetle has escaped detection in Fagus in its presently unknown native range, it is clear that more investigations must be undertaken to discover the true native and introduced distribution and host range of an elusive and potentially invasive species.

ACKNOWLEDGEMENTS. We gratefully acknowledge the staff at Green-Wood Cemetery (particularly J. Charap, S. Evans, S. Wells, and J. Figueroa) for their assistance with rearing, trapping and obtaining host material. E.R. Hoebeke (University of Georgia, Athens, GA, USA) examined specimens and provided valuable guidance with initial identification. J. Cancelliere (New York State Department of Conservation and Recreation, Albany, NY, USA) provided traps and lures. K. Dodds and M. Bohne (USDA Forest Service, Durham, NH, USA), as well as two anonymous reviewers critically read and provided valuable suggestions to improve the manuscript.

\section{REFERENCES}

Agosta S.J. \& Klemens J.A. 2008: Ecological fitting by phenotypically flexible genotypes: implications for species associations, community assembly and evolution. - Ecol. Lett. 11: $1123-1134$.

Anonymous 1894: A new pear insect. — Insect Life 7: 258-260.

Aukema J.E., Leung B., Kovacs K., Chivers C., Britton K.O., Englin J., Frankel S.J., Haight R.G., Holmes T.P., Liebhold A.M. ET AL. 2011: Economic impacts of non-native forest insects in the continental United States. - PLOS ONE 6(9): e24587, 7 pp.

Baranchikov Y., Mozolevskaya E., Yurchenko G. \& Kenis M. 2008: Occurrence of the emerald ash borer, Agrilus planipennis, in Russia and its potential impact on European forestry. EPPO Bull. 38: 233-238.

Bernhard D., Fritzsch G., Glöckner P. \& Wurst C. 2005: Molecular insights into speciation in the Agrilus viridis-complex and the genus Trachys (Coleoptera: Buprestidae). - Eur. J. Entomol. 102: 599-605.

BílÝ S. 1991: Two new species of Agrilus roscidus species-group from central Europe (Coleoptera, Buprestidae). - Acta Entomol. Bohemoslov. 88: 371-375.

BílÝ S. 2002: Summary of the bionomy of the Buprestid beetles of Central Europe (Coleoptera: Buprestidae). - Acta Entomol. Mus. Natn. Pragae (Suppl.) 10: 1-104, 16 pls.

Bright D.A. 1987: The Metallic Wood-Boring Beetles of Canada and Alaska (Coleoptera: Buprestidae). The Insects and Arachnids of Canada, Part 15. Agriculture Canada Research Branch Publication 1810, Ottawa, 335 pp.

Browne F.G. 1968: Pest and Diseases of Forest Plantation Trees. An Annotated List of the Principal Species Occurring in the British Commonwealth. Clarendon Press, Oxford, xi+1330 pp.

Calcagno V., Thomas Y. \& Bourguet D. 2007: Sympatric host races of the European corn borer: adaptation to host plants and hybrid performance. - J. Evol. Biol. 20: 1720-1729.

Campbell C.L. \& McCaffrey J.P. 1991: Population trends, seasonal phenology, and impact of Chrysolina quadrigemina, $C$. hyperici (Coleoptera: Chrysomelidae), and Agrilus hyperici (Coleoptera: Buprestidae) associated with Hypericum perforatum in northern Idaho. - Environ. Entomol. 20: 303-315.

Chamorro M.L., Volkovitsh M.G., Poland T.M., HaAck R.A. \& Lingafelter S.W. 2012: Preimaginal stages of the emerald ash borer, Agrilus planipennis Fairmaire (Coleoptera: Buprestidae): an invasive pest on ash trees (Fraxinus). - PLoS ONE 7(3): e33185, $12 \mathrm{pp}$.

Cipollini D. 2015: White fringetree as a novel larval host for emerald ash borer. - J. Econ. Entomol. 108: 370-375. 
Cipollini D. \& Peterson D.L. 2018: The potential for host switching via ecological fitting in the emerald ash borer-host plant system. - Oecologia 187: 507-519.

Cipollini D. \& Rigsby C.M. 2015: Incidence of infestation and larval success of emerald ash borer (Agrilus planipennis) on white fringetree (Chionanthus virginicus), Chinese fringetree (Chionanthus retusus), and devilwood (Osmanthus americanus). - Environ. Entomol. 44: 1375-1383.

Costanza K.K.L., Livingston W.H., Kashian D.M., Slesak R.A., TardiF J.C., Dech J.P., Diamond A.K., Daigle J.J., Ranco D.J., NePtUNE J.S. ET AL. 2017: The precarious state of a cultural keystone species: tribal and biological assessments of the role and future of black ash. - J. Forestry 115: 435-446.

Evans A.M., McKenna D.D., Bellamy C.L. \& Farrell B.D. 2015: Large-scale molecular phylogeny of metallic wood-boring beetles (Coleoptera: Buprestoidea) provides new insights into relationships and reveals multiple evolutionary origins of the larval leaf-mining habit. — Syst. Entomol. 40: 385-400.

Felsenstern J. 1985: Confidence limits on phylogenies: an approach using the bootstrap. - Evolution 39: 783-791.

FISHER W.S. 1928: A revision of North American species of the buprestid beetles belonging to the genus Agrilus. - Bull. U.S. Natn. Mus. 145: 1-347.

Frost S.W. 1922: Occurence of Agrilus coeruleus Rossi in America. - Can. Entomol. 54: 96.

HaAck R.A., Jendek E., Liu H., Kenneth R.M., Petrice T.R., PoLAND T.M. \& Ye H. 2002: The emerald ash borer: a new exotic pest in North America. — Newsl. Michigan Entomol. Soc. 47: $1-5$.

Hanski I., Wirta H., Nyman T. \& Rahagalala P. 2008: Resource shifts in Malagasy dung beetles: contrasting processes revealed by dissimilar spatial genetic patterns. - Ecol. Lett. 11: 12081215.

Hebert P.D.N., Cywinska A., Ball S.L. \& deWaArd J.R. 2003 Biological identifications through DNA barcodes. - Proc. $R$. Soc. Lond. (B) 270: 313-321.

Herms D.A. \& McCullough D.G. 2014: Emerald ash borer invasion of North America: History, biology, ecology, impacts, and management. - Annu. Rev. Entomol. 59: 13-30.

Hespenheide H.A. 1968: An immigrant Agrilus (Coleoptera: Buprestidae). - Entomol. News 79(3): 76-80.

Hizal E. \& ArslangündoĞdu Z. 2018: The first record of twolined chestnut borer Agrilus bilineatus (Weber, 1801) (Coleoptera: Buprestidae) from Europe. - Entomol. News 127: $333-335$.

Hoebeke E.R., Jendek E., Zablotny J.E., Rieder R., Yoo R., GreBENNIKOV V.V. \& REN L. 2017: First North American records of the eastasian metallic wood-boring beetle Agrilus smaragdifrons Ganglbauer (Coleoptera: Buprestidae: Agrilinae), a specialist on tree of heaven (Ailanthus altissima, Simaroubaceae). - Proc. Entomol. Soc. Wash. 119: 408-423.

JANZEN D.H. 1985: On ecological fitting. — Oikos 45: 308-310.

Jendek E. \& Grebennikov V.V. 2009: Agrilus sulcicollis (Coleoptera: Buprestidae) a new alien species in North America. Can. Entomol. 141: 236-245.

Jendek E. \& Grebennikov V.V. 2011: Agrilus (Coleoptera, Buprestidae) of East Asia. Jan Farkač, Prague, 362 pp. Available from: https://www.researchgate.net/publication/269700572 Agrilus_Coleoptera_Buprestidae_of_East_Asia

Jendek E. \& Polákoví J. 2014: Host Plants of World Agrilus (Coleoptera, Buprestidae). A Critical Review. Springer, Heidelberg, New York, Dordrecht, London, 706 pp.

Jendek E., Grebennikov V.V. \& BocaK L. 2015: Undetected for a century: Palaearctic Agrilus ribesi Schaefer (Coleoptera: Bu- prestidae) on currant in North America, with adult morphology, larval biology and DNA barcode. - Zootaxa 4034: 112-126.

Jones T.S., Bilton A.R., MaK L. \& Sait S.M. 2015: Host switching in a generalist parasitoid: contrasting transient and transgenerational costs associated with novel and original host species. - Ecol. Evol. 5: 459-465.

KatoH K., Rozewicki J. \& Yamada K.D. 2017: MAFFT online service: multiple sequence alignment, interactive sequence choice and visualization. - Brief. Bioinform. 2017: 108, 7 pp.

Kelnarova I., Jendek E., Grebennikov V.V. \& Bocak L. 2019: First molecular phylogeny of Agrilus (Coleoptera: Buprestidae), the largest genus on Earth, with DNA barcode database for forestry pest diagnostics. - Bull. Entomol. Res. 109: 200211.

Klooster W.S., Gandhi K.J.K., Long L.C., Perry K.I., Rice K.B., \& Herms D.A. 2018: Ecological impacts of emerald ash borer in forests at the epicenter of the invasion in North America. Forests 9: 250, 14 pp.

Kuraku S., Zmasek C.M., Nishimura O. \& Katoh K. 2013: aLeaves facilitates on-demand exploration of metazoan gene family trees on MAFFT sequence alignment server with enhanced interactivity. - Nucl. Acids Res. 41: W22-W28.

MALKIN B. 1941: A European buprestid in the United States. Bull. Brooklyn Entomol. Soc. 36: 132.

Miller M., Pfeiffer W. \& Schwartz T. 2010: Creating the CIPRES Science Gateway for inference of large phylogenetic trees. In: Proceedings of the Gateway Computing Environments Workshop (GCE), New Orleans, LA. Institute of Electrical and Electronics Engineers, Piscataway, NJ, pp. 1-8.

Niehuis M. \& Tezcan S. 1993: Beitrag zur Kenntnis der AgrilusArten der Türkei (Coleoptera: Buprestidae). — Mitt. Int. Entomol. Ver. 18: 1-74.

PÉNEAU J. 1911: Coléoptères de la Loire-Inférieure. (Suite) (1). - Bull. Soc. Sci. Nat. Ouest Fr. (Troisième série, Tome I, Premiére partie): 51[205]-114[268].

Popper K. 1959: The Logic of Scientific Discovery. Basic Books, New York, 484 pp.

Rambaut A. 2019: FigTree. Ver. 1.4.0. Program and Documentation. URL: http://ree.bio.ed.ac.uk/software/figtree/.

Ratnasingham S. \& Hebert P.D.N. 2007: BOLD: The Barcode of Life Data System (http://www. barcodinglife. org). - Mol. Ecol. Notes 7: 355-364.

Rossi W. 2011: New species of Laboulbenia from Ecuador, with evidence for host switch in the Laboulbeniales. - Mycologia 103: 184-194.

Siegert N.W., McCullough D.G., Liebhold A.M. \& Telewski F.W. 2014: Dendrochronological reconstruction of the epicentre and early spread of emerald ash borer in North America. Divers. Distrib. 20: 847-858.

Stamatakis A. 2014: RAxML version 8: a tool for phylogenetic analysis and post-analysis of large phylogenies. - Bioinformatics 30: 1312-1313.

Stamatakis A., Hoover P. \& Rougemont J. 2008: A rapid bootstrap algorithm for the RAxML web servers. - Syst. Biol. 57: 758-771.

WeIss H.B. 1914: Notes on three imported insects occurring in New Jersey. - J. Econ. Entomol. 7: 250-251.

Westcott R.L. 2007: The exotic Agrilus subrobustus (Coleoptera: Buprestidae) is found in northern Georgia. - Coleopt. Bull. 61: 111-112.

Received April 25, 2019; revised and accepted July 10, 2019 Published online July 19, 2019 


\section{Supplementary files:}

Fig. S1 (http://www.eje.cz/2019/028/S01.pdf). Result of analysis A1. Neighbour Joining unrooted clustering of 759 Agrilus jewel beetles for which DNA barcodes between 400 and $680 \mathrm{bp}$ in length were analyzed using the online BOLD (www.boldsystem. org) alignment and tree-building engine (distance model: Kimura 2 parameter)
Fig. S2 (http://www.eje.cz/2019/028/S02.pdf). Result of analysis A2. Rooted phylogram of 759 Agrilus jewel beetles for which DNA barcodes between 400 and 680 bp in length were analyzed using CIPRES Science Gateway online platform and the Maximum Likelihood method as implemented in RAxML 8. Topology is rooted on a specimen of Pachyschelus. Digits on branches are bootstrap values. 